\title{
Table Contents of Special Issue
}

\section{Thioactamide-induced liver damage in zebrafish embryo as a disease model for Steatohepatitis}

Hepatic steatosis is a prerequisite for subsequent events leading to liver injury, fibrosis, cirrhosis and carcinoma. There are no animal models for the steatohepatitis [1]. In this study, steatohepatitis was induced in zebrafish embryo by thioacetamide (TAA). After five-day post-fertilization, apoptosis was increased by up-regulation of Bad, Bax, p38a, caspase- 3 and -8 , and $\mathrm{JNK}-1$, and accumulation of fatty droplets was observed. Up-regulation of steatosis markers such as ACC, adiponectin, PTL, CEBP-ö and -ö, SREBP-1 and glutathione peroxidase was found. Therefore, it suggests that TAAtreated zebrafish could serve as an animal model for studying molecular mechanism of steatohepatitis and screening of anti-steatohepatitis drugs [2].

\section{Identification of differentially expressed genes in clear cell renal cell carcinoma by analysis of full- length enriched cDNA library}

Renal cell carcinoma (RCC) affects approximately 150,000 people worldwide each year, causing close to 78,000 deaths annually [3]. Clear cell RCC (ccRCC) is the most common, accounting for $\sim 80$ ]] $>\%$ of RCC [4]. Tang etôCPáal. [5] used the full-length cDNA libraries of ccRCC and normal kidney tissues to identify the differentially expressed genes in ccRCC. They observed obvious changes in the expressions of cytoskeleton, immune, metabolism, signal transduction, translation, and chaperon related genes between ccRCC and normal kidney tissues. Furthermore, the up-regulation of annexin A2 gene and the down-regulation of argininosuccinate synthetase gene, confirmed by Western blot analysis and quantitative real-time PCR analysis in 45 pairs of RCC and adjacent non-tumor tissues, were found.

\section{Gene expression analysis of human hepatocellular carcinoma by using full-length cDNA library}

Hepatocellular carcinoma (HCC) is a leading cause of death worldwide. Hepatitis B virus or hepatitis $\mathrm{C}$ virus infection has been shown to cause hepatic carcinogenesis [6]. Based on the analytic results of full-length cDNA library [7], 180 and 279 of genes were shown to have increased and decreased expression patterns in $\mathrm{HCC}$, respectively. The candidate genes consisted of the genes encoding liver-specific metabolism enzymes, secretory functional proteins, proteases and their inhibitors, protein chaperon, cell cycle components, apoptosis-related proteins, transcriptional factors, and DNA binding proteins. Several genes were further investigated by using real-time PCR to confirm the gene expression levels in at least 24 pairs of HCC and adjacent non-tumor tissues. The results showed that genes encoding reticulon 4, RGS-1, antiplasmin, and kallikrein B were downregulated with the average of 2.8-, 8.5-, 3.2-, and 10.5-fold, respectively [8]. These results provide crucial candidate genes to develop clinical diagnosis and gene therapy of HCC.

\section{Calcineurin in Porphyromonas gingivalis-induced myocardial hypertrophy and apoptosis}

Cardiac myocyte hypertrophy and apoptosis may occur in a variety of diseases, such as hypertension, myocardial infarction, endocrine disorders, toxicants, and bacterial endocarditis [9, 10]. Calcineurin was considered as an essential mediator of cardiac hypertrophy and apoptosis, and in most studies, calcineurin inhibitors attenuated cardiac hypertrophy in vivo and also attenuated apoptosis of cardiac myocytes [11]. Calcineurin and its direct downstream transcriptional effector NFAT-3 potentially play a regulatory role for maladaptive hypertrophy and heart failure [12]. The aim of this study was to clarify the role of calcineurin signaling pathway in $P$. gingivalis-induced $\mathrm{H} 9 \mathrm{c} 2$ myocardial cell hypertrophy and apoptosis. Results showed that $P$. gingivalis not only increased calcineurin protein, NFAT-3 protein products and cellular hypertrophy, but also increased DNA fragmentation, nuclear condensation and Bad protein products in $\mathrm{H} 9 \mathrm{c} 2$ cells. The increased cellular sizes, DNA fragmentation, nuclear condensation, and $\mathrm{Bad}$ of $\mathrm{H} 9 \mathrm{c} 2$ cells treated with 
$P$. gingivalis were all significantly reduced after pre-administration of CsA. This study suggests that the activity of calcineurin signal pathway may be initiated by $P$. gingivalis and further lead to cell hypertrophy and death in cultured $\mathrm{H} 9 \mathrm{c} 2$ myocardial cells [13].

\section{Tumor necrosis factor-alpha induces caspase-inde- pendent cell death in human neutrophils via reactive oxidants and associated with calpain activity}

Neutrophils have relatively short life spans, although they are present in large numbers in blood and are produced in large quantities in the bone marrow. As neutrophils have been implicated in the pathogenesis in human diseases [14], it is important to understand molecular mechanisms that govern neutrophil homeostasis. Liu et al. report here that neutrophils undergo TNF-alpha mediated apoptosis in a caspase-independent fashion [15]. Furthermore, it was shown that this caspase-independent death mechanism was related to increased calpain and oxidative activities. Thus, there exist caspase-dependent and -independent and perhaps still as yet unknown death pathways that govern neutrophil homeostasis.

\section{References}

1. Reid A.E., Nonalcoholic steatohepatitis. Gastroenterology 121: 710-723, 2001.

2. Amali A.A., Rekha R.D., Lin C.J.F., Wang W.L., Gong H.Y., Her G.M. and Wu J.L., Thioacetamide induced liver damage in zebrafish embryo as a disease model for Steatohepatitis. J. Biomed. Sci. (this issue).

3. Pavlovich C.P. and Schmidt L.S., Searching for the hereditary causes of renal-cell carcinoma. Nat. Rev. Cancer 4(5): 381-393, 2004.

4. Cheville J.C., Lohse C.M., Zincke H., Weaver A.L. and Blute M.L., Comparisons of outcome and prognostic features among histologic subtypes of renal cell carcinoma. Am. J. Surg. Pathol. 27(5): 612-624, 2003.
5. Tang S.W., Chang W.H., Chao Y.W., Lin C.Y., Chen H.F., Lai Y.H., Zhan B.W., Su Y.C., Jane S.W., Chen Y.C., Hsu C.I., Lin W.C., Wang K.C., Lai M.K. and Lin J.Y., Identification of differentially expressed genes in clear cell renal cell carcinoma by analysis of full-length enriched cDNA library. J. Biomed. Sci. (this issue).

6. Buendia M.A., Genetics of hepatocellular carcinoma. Semin. Cancer. Biol. 10: 185-200, 2000

7. Tsai C.C., Chung Y.D., Lee H.J., Chang W.H., Suzuki Y., Sugano S. and Lin J.Y., Large-scale sequencing analysis of the full-length cDNA library of human hepatocellular carcinoma. J. Biomed. Sci. 10: 636-643, 2003.

8. Tsai C.C., Huang K.W., Chen H.F., Zhan B.W., Lai Y.H., Lee F.H., Lin C.Y., Ho Y.C., Chao Y.W., Su Y.C., Jane S.W., Chen Y.C., Hsu C.I., Li P.H., Hsu H.C., Suzuki Y., Sugano S. and Lin J.Y., Gene expression analysis of human hepatocellular carcinoma by using full-length cDNA library. J. Biomed. Sci. (this issue).

9. Gill C., Mestril R. and Samali A., Losing heart: the role of apoptosis in heart disease - a novel therapeutic target?. FASEB J. 16: 135-146, 2002.

10. Dhalla N.S., Ziegelhoffer A., Singal P.K., Panagia V. and Dhillon K.S., Subcellular changes during cardiac hypertrophy and heart failure due to bacterial endocarditis. Basic Res. Cardiol. 75: 81-91, 1980.

11. Saito S., Hiroi Y., Zou Y., Aikawa R., Toko H., Shibasaki F., Yazaki Y., Nagai R. and Komuro I., beta-Adrenergic pathway induces apoptosis through calcineurin activation in cardiac myocytes. J. Biol. Chem. 275: 34528-34533, 2000 .

12. Wilkins B.J., Dai Y.S., Bueno O.F., Parsons S.A., Xu J., Plank D.M., Jones F., Kimball T.R. and Molkentin J.D., Calcineurin/NFAT coupling participates in pathological, but not physiological, cardiac hypertrophy. Circ. Res. 94: 110-118, 2004.

13. Lee S.D., Kuo W.W., Lin D.Y., Chen T.H., Kuo W.H., Hsu H.H., Chen J.Z., Liu J.Y. and Huang C.Y., Role of calcineurin in Porphyromonas gingivalis-induced myocardial cell hypertrophy and apoptosis. J. Biomed. Sci. (this issue).

14. Lee A., Whyte M.K. and Haslett C., Inhibition of apoptosis and prolongation of neutrophil functional longevity by inflammatory mediators. J. Leukoc. Biol. 54: 283288, 1993.

15. Chen H.C., Wang C.J., Chou C.L., Lin S.M., Huang C.D., Lin T.Y., Wang C.H., Lin H.C., Yu C.T., Kuo H.P. and Liu C.Y., Tumor necrosis factor- $\alpha$ induces caspase-independent cell death in human neutrophils via reactive oxidants and associated with calpain activity. J. Biomed. Sci. (this issue). 